\title{
POTENSI PENERAPAN SISTEM RFID MOBIL DI KAWASAN UNS
}

\author{
Ressyana Nur E ${ }^{1}$, Dewi Handayani ${ }^{2}$, Agus Sumarsono ${ }^{3}$ \\ Program Studi Teknik Sipil, Fakultas Teknik, Universitas Sebelas maret \\ Jl. Ir. Sutami Nomor 36A Kentingan Surakarta 57126, Surakarta \\ Email : Ithana.permata1@gmail.com
}

\begin{abstract}
ABSTRAK
Jurnal ini merupakan publikasi dari penelitian yang telah di lakukan yang berhubungan dengan sistem parkir di Universitas Sebelas Maret Surakarta. Sistem parkir yang digunakan adalah RFID (Radio Frequency Indentification). Dengan jumlah iventarisasi parkir terhadap jumlah kebutuhan parkir. Hasil dari penelitian ini adalah mengetahui jumlah iventarisasi parkir yang tersedia sejumlah 1398 dengan kebutuhan parkir terbesar adalah 860 dan rekomendasi untuk penerapan sisitem RFID mobil di kawasan UNS.
\end{abstract}

Kata Kunci : Satuan Ruang Parkir (SRP), Kebutuhan Parkir, RFID (Radio Frequency Identification)

\begin{abstract}
ABSTRACK
This journal is a publication of research that has been done in connection with the parking system at Sebelas Maret University Surakarta. Parking system used is RFID (radio frequency indentification). With the number of parking iventarisasi against the amount of parking needs. The result of this research is to know the number of available parking inventory of 1398 with the biggest parking requirement is 860 and the recommendation for the application of vehicle RFID system in UNS region.
\end{abstract}

Keywords : Unit Parking Space (SRP), Parking Requirement, RFID (Radio Frequency Identification)

\section{PENDAHULUAN}

Tempat parkir dan sistem pengaturan perparkiran adalah komponen penting dan tidak dapat dipisahkan dalam pelayanan sebuah fasilitas umum. Keberadaan sistem perparkiran yang baik akan mendukung fasilitas umum yang digunakan oleh banyak pihak. Sistem parkir yang baik mencerminkan kebaikan sistem yang lebih luas dalam fasilitas umum tersebut. Peningkatan jumlah mahasiswayang diterima di UNS dan penambahan dosen dan karyawan baru, secara langsung mengakibatkan peningkatan jumlah pengguna kendaraan baik roda dua maupun roda empat di UNS. Sebagai kampus berwawasan ramah lingkungan, UNS menempati peringkat 76 di dunia, dan 5 di Indonesia. Penilaian tersebut dikeluarkan oleh UI Green Metric World University Rangking pada Januari 2017 terhadap aspek kinerja kampus hijau (Green Campus) pada tahun 2016.

Salah satu misi dalam Green Campus adalah membatasi jumlah kendaraan bermotor yang digunakan dalam kampus, dan kebijakan untuk mengurangi lahan/area parkir di kampus diharapkan akan mendorong civitas akademika akan beralih ke penggunaan bus, penggunaan 
sepeda atau berjalan kaki dalam beraktitas di lingkungan kampus. Teknologi yang dapat menjawab permasalahan sistem perparkiran UNS adalah teknologi Radio Frequency Identification (RFID). Pada sistem perparkiran yang menggunakan teknologi RFID, petugas tidak perlu lagi mencatat dan mengecek secara manual dan berulang-ulang setiap kendaraan yang keluar masuk, karena sudah dilakukan otomatis oleh komputer.

Adapun tujuan penelitian ini adalah :

a. Mendapatkan data jumlah ketersedian Satuan Ruang Parkir (SRP) terhadap kebutuhan Satuan Ruang Parkir (SRP) mobil penumpang di kawasan Kampus UNS.

b. Mengetahui potensi implementasi RFID mobil di kawasan Kampus UNS.

c. Mendapatkan rekomendasi sistem implementasi RFID mobil di kawasan Kampus UNS.

\section{TINJAUAN PUSTAKA}

\section{Parkir}

Ada beberapa pengertian dasar tentang parkir yang diantaranya dapat dilihat sebagai berikut:

a. Parkir adalah keadaan tidak bergerak suatu kendaraan yang tidak bersifat sementara (PP No. 43 Th. 1993);

b. Parkir adalah Tempat khusus bagi kendaraan untuk berhenti demi keselamatan (Ofyar Th. 2000), dan;

c. Parkir adalah tempat pemberhentian kendaraan dalam jangka waktu pendek atau lama, sesuai dengan kebutuhan pengendara (Rekayasa Lalu Lintas Th. 2002).

\section{Fasilitas Parkir}

Fasilitas parkir untuk umum di luar badan jalan dapat berupa taman parkir dan atau gedung parkir. Di luar badan jalan antara lain pada kawasan- kawasan tertentu seperti pusat- pusat perbelanjaan, bisnis maupun perkantoran yang menyediakan fasilitas parkir untuk umum. (Pedoman Perencanaan dan Pengoperasian Fasilitas Parkir, Direktorat Jenderal Perhubungan Darat 1998). Berdasarkan cara penempatannya dan dalam operasional sehari-hari fasilitas parkir terdiri dari:

a. Fasilitas Parkir Pada Badan Jalan (on street parking).

b. Fasilitas Parkir di Luar Badan Jalan (off street parking).

\section{Satuan Ruang Parkir}

Dasar Pertimbangan Satuan Ruang Parkir (SRP)

Berdasarkan Pedoman Perencanaan dan Pengoperasian Fasilitas Parkir hal-hal yang menjadi pertimbangan dalam menentukan satuan ruang parkir adalah:

1. Dimensi kendaraan standar untuk mobil penumpang.

2. Ruang bebas kendaraan parkir

3. Lebar bukaan pintu kendaraan 


\section{Penentuan Satuan Ruang Parkir}

Berdasarkan pertimbangan-pertimbangan di atas maka penentuan Satuan Ruang Parkir (SRP) dibagi menjadi tiga jenis kendaraan dan berdasarkan penentuan SRP untuk mobil penumpang diklasifikasikan menjadi tiga golongan, seperti pada Tabel berikut :

Tabel 1 Penentuan Satuan Ruang Parkir (SRP)

\begin{tabular}{lc}
\hline \multicolumn{1}{c}{ Jenis Kendaraan } & Satuan Ruang Parkir $\left(\mathbf{m}^{2}\right)$ \\
\hline 1. a. Mobil Penumpang untuk Golongan I & $2,30 \times 5,00$ \\
b. Mobil Penumpang untuk Golongan II & $2,50 \times 5,00$ \\
c. Mobil Penumpang untuk Golongan III & $3,00 \times 5,00$ \\
2. Bus / truk & $3,40 \times 12,50$ \\
3. Sepeda motor & $0,75 \times 2,00$ \\
\hline
\end{tabular}

Sumber: Pedoman Perencanaan dan Pengoperasian Fasilitas Parkir Direktorat Jenderal Perhubungan Darat 1998

\section{Pengertian RFID}

RFID (Radio Frequency Identification) adalah teknologi yang menggunakan gelombang radio untuk mengidentifikasi orang atau suatu obyek secara otomatis dengan menggunakan tag. Teknologi ini mencipatakan cara otomatis untuk mengumpulkan informasi suatu produk, tempat, waktu atau transaksi lebih cepat dan mudah tanpa buman error.

RFID (Kenzeller, 1999) adalah teknologi identifikasi yang fleksibel, mudah digunakan, dan sangat cocok untuk operasi otamatis. RFID mengkombinasikan keunggulan yang tidak tersedia pada teknologi identifikasi yang lain, RFID dapat disediakan dalam devais yang hanya dapat di baca saja (Read Only) atau dapat dibaca dan ditulis (Read/Write), tidak memerlukan kontak langsung maupun jalur cahaya untk dapat beroperasi, dapat berfungsi pada berbagai variasi kondisi lingkungan, dan menyediakan tingkat integritas data yang tinngi. Sebagai tambahan, karena teknologi ini sulit untuk dipalsukan, maka RFID dapat menyediakan tingkat keamanan yang tinngi.

\section{Alur Kerja Sistem Parkir dengan RFID}

Sistem parkir dan pentarifannya yang berbasis RFID dan basis data ini memeliki tahapan kerja sebagai berikut :

1. Ketika ada calon pengguna lahan parkir yang datang, operator pc di gerbang masuk mendekatkan 1 buah RFID tag ke reader, agar ID uniknya dapat terbaca, dan kemudian dikirimkan ke PC dengan komunikasi binary serial. ID unik tersebut ditampilkan pada perangkat lunak yang berperan sebagai antar-muka.

2. Operator mencatat nomor kendaraan calon pengguna lahan parkir tersebut pada perangkat lunak, dan kemudian melakukan input ke basis data. 
3. Perangkat lunak menyimpan data-data pengguna lahan parkir yang baru masuk pada basis data. Data-data yang disimpan meliputi ID unik tag, nomor kendaraan, kategori pengguna lahan parkir tersebu, dan jam masuk.

4. Kemudian tag tersebut diberikan kepada pengguna lahan parkir sebagai kartu tanda parkir yang unik dan tidak boleh hilang.

5. Ketika ada pengguna areal parkir yang akan keluar areal parkir, pengguna tersebut menyerahkan kartu parkir yang ia dapatkan ketika masuk yang berupa tag, kepada operator.

6. Kemudian opertor meletakan tag tersebut dekat reader, kembali reader membaca ID unik dari tag tersebut, dan kemudian mengirmkan datanya ke PC. ID unik tersebut kemudian diolah oleh perangkat lunak tersebut, dan mengambil data-data dari basis denagan ID unik tag yang sesuai. Kemudian data-data tersebut ditampilkan pada perangkat lunak tersebut.

7. Kemudian perangkat lunak tersebut juga melakukan pengecekan kategori pengguna area parkir tersebut, dan melakukan pentarifan dengan kategori yang sesuai.

8. Apabila kartu tag hilang, maka akan dilakukan prosuder tambahan.

\section{METODE PENELITIAN}

\section{Lokasi Penelitian}

Lokasi berada di lokasi Kampus Universitas Sebelas Maret Surakarta, JL. Ir. Sutami nomor $36 \mathrm{~A}$

\section{Survei Pendahuluan}

Survei pendahuuan dilakukan sebelum melakukan survei di lapangan, survei pendahuluan bertujuan untuk mengetahui:

a. Persentase jumlah distribusi responden yang diambil

Untuk menentukan jumlah responden untuk distribusi kuesioner yang akan dibagikan kepada dosen,mahasiswa dan karyawan di kawasan UNS.

b. Lokasi dan Waktu pengambilan data.

Lokasi pengambilan data dilakukan di kawasan Kampus UNS sendiri. Sedangkan waktu pengambilan data di lakukan pada hari Senin dikarenkan pada hari Senin hari pertama kerja untuk dosen/karyawan dan hari pertama mahasiswa masuk kuliah. Survei pengambilan data dilakukan pada pukul 10.00-11.00 WIB, karena pada jam tersebut dalam penilitian sebelumnya Raffel (2016) merupakan jam sibuk di kawasan Kampus UNS. 


\section{Pengumpulan Data}

Pengumpulan data dilakukan dengan Survai Inventarisasi parkir, Survai kebutuhan parkir dan survei kuesioner. Metode Inventarisasi Parkir dilakukan dengan tujuan untuk mnegetahui kapasitas dan fasilitas ruang parkir yang tersedia. Survei inventarisai ini dilakukan dengan melihat lokasi perparkiran UNS, jenis ruang parkir, jumlah parkir yang tersedia. Survai kebutuhan parkir dilakukan berdasarkan hasil survei lapangan dengan mencatat dan menghitung seluruh kendaraan yang telah diparkir dan berada dalam kawasan kampus UNS.

\section{PEMBAHASAN}

\section{Inventarisasi parkir}

Inventarisai ruang parkir adalah untuk menegetahui fasilitas ruang parkir yang tersedia. Informasi ini dijadikan dasar untuk mengetahui kebutuhan ruang parkir yang harus disediakan dan guna memenuhi kebutuhan untuk masa yanga akan datang. Perhitungan Satuan Ruang Parkir (SRP) di dasarkan beberapa hal berikut ini :

a. Untuk area yang sudah bermarka dihitung berdasarkan jumlah marka yang ada.

b. Untuk area yang belum bermarka dihitung berdasarkan luas area Satuan Ruang Parkir setelah dikurangi $20 \%$ untuk keperluan manuver.

Inventarisasi di Universitas Sebelas Maret ini di bagi menjadi 7 zona yaitu zona A, zona B, zona $\mathrm{C}$, zona $\mathrm{D}$, zona $\mathrm{E}$, zona $\mathrm{F}$ dan Zona $\mathrm{G}$.

Jumlah Satuan Ruang Parkir pada masing - masing zona adalah zona A sebesar 404, zona B sebesar 271, zona C sebesar 136, zona D sebesar 250, zona E sebesar 159 dan zona G sebesar178.

$\mathrm{SRP}=404+271+136+250+159+178$

$\mathrm{SRP}=1398$

Sehingga didapatkan total Satuan Ruang Parkir di kawasan UNS sebesar 1398 Satuan Ruang Parkir.

\section{Kebutuhan parkir}

Kebutuhan parkir diperoleh dari data sekunder dalam penilitian sebelumnya yang dilakukan oleh raffel (2016) mendapatakan volume parkir di UNS selama 10 jam survei (07.99-17.00 WIB) sebesar 2757 pengguna mpbil. Akumulasi parkir trtinggi di UNS terjadi pada jam 10.15-10.30 WIB dengan jumlah kendaraan sebanyak 860 kendaran roda empat. 


\section{Potensi Implementasi RFID Mobil}

Potensi implementasi RFID mobil di kawasan kampus Universitas Sebelas Maret berdasar data kuesioner yang telah di sebar di beberapa fakultas. Yang di isi oleh mahasiswa dan dosen. Persebaran responden sebagai berikut :

Mahasiswa

Tabel 2 Jumlah Responden mahasiswa

\begin{tabular}{llll}
\hline No & Fakultas & $\begin{array}{l}\text { Total } \\
\text { Mahasiswa }\end{array}$ & Responden \\
\hline $\mathbf{1}$ & Seni rupa dan desain & 950 & 8 \\
$\mathbf{2}$ & Ilmu sosial dan ilmu politik & 2794 & 10 \\
$\mathbf{3}$ & Hukum & 1695 & 6 \\
$\mathbf{4}$ & Ekonomi dan bisnis & 2705 & 10 \\
$\mathbf{5}$ & Kedokteran & 2031 & 20 \\
$\mathbf{6}$ & Pertanian & 3042 & 11 \\
$\mathbf{7}$ & Teknik & 2563 & 9 \\
$\mathbf{8}$ & Keguruan dan ilmu Pendidikan & 7833 & 10 \\
$\mathbf{9}$ & MIPA & 2172 & 10 \\
$\mathbf{1 0}$ & Ilmu budaya & 1723 & 6 \\
\hline Total & & 27508 & 100 \\
\hline
\end{tabular}

Dosen / karyawan

Tabel 3 Jumlah Responden Dosen / Karyawan

\begin{tabular}{llll}
\hline No & Fakultas & Total Dosen & Responden \\
\hline $\mathbf{1}$ & Seni rupa dan desain & 57 & 4 \\
$\mathbf{2}$ & Ilmu sosial dan ilmu politik & 96 & 6 \\
$\mathbf{3}$ & Hukum & 90 & 6 \\
$\mathbf{4}$ & Ekonomi dan bisnis & 147 & 9 \\
$\mathbf{5}$ & Kedokteran & 202 & 13 \\
$\mathbf{6}$ & Pertanian & 156 & 10 \\
$\mathbf{7}$ & Teknik & 197 & 12 \\
$\mathbf{8}$ & Keguruan dan ilmu Pendidikan & 407 & 26 \\
$\mathbf{9}$ & MIPA & 144 & 9 \\
$\mathbf{1 0}$ & Ilmu budaya & 99 & 6 \\
\hline Total & & 100 \\
\hline
\end{tabular}


Adapun hasil dari penyebaran kuesioner ini adalah :

Jenis Kelamin

Tabulasi rekapitulasi data hasil survei menurut jenis kelamin dapat dilihat pada tabel beikut :

Tabel 4 Porposi Responden Berdasarkan Jenis Kelamin

\begin{tabular}{|c|c|c|c|}
\hline No & Jenis Kelamin & Jumlah & $\begin{array}{l}\text { Presentase } \\
(\%)\end{array}$ \\
\hline 1 & LAKI-LAKI & 115 & 57 \\
\hline 2 & PEREMPUAN & 85 & 43 \\
\hline \multicolumn{2}{|c|}{ Jumlah } & 200 & 100 \\
\hline
\end{tabular}

Usia

Hasil pelaksanaan survei karakteristik penumpang menurut kelompok usia dapat dilihat dalam tabel berikut :

Tabel 5 Porposi Responden Berdasarkan Usia

\begin{tabular}{llll}
\hline No & Usia (tahun) & Jumlah & Presentase (\%) \\
\hline $\mathbf{1}$ & $18-27$ & 100 & 50 \\
$\mathbf{2}$ & $28-37$ & 26 & 13 \\
$\mathbf{3}$ & $38-47$ & 27 & 13 \\
$\mathbf{4}$ & $>47$ & 47 & 24 \\
\hline Jumlah & & 200 & 100 \\
\hline
\end{tabular}

Frekuensi parkir

Hasil pelaksanaan survei karakteristik penumpang menurut kelompok Frekuensi parkir dapat dilihat dalam tabel :

Tabel 6 Porposi Responden Berdasarkan Frekuensi Parkir

\begin{tabular}{llll}
\hline No & Frekuensi Parkir/minggu & Jumlah & Presentase (\%) \\
\cline { 3 - 4 } $\mathbf{1}$ & $<=3$ & 47 & 50 \\
$\mathbf{2}$ & 4 & 35 & 17 \\
$\mathbf{3}$ & 5 & 99 & 23 \\
$\mathbf{4}$ & $>5$ & 19 & 10 \\
\hline Jumlah & 200 & 100 \\
\hline
\end{tabular}


Penerapan sistem RFID

Hasil pelaksanaan survei karakteristik penumpang menurut kelompok Penerapan Sistem RFID dapat dilihat dalam tabel :

Tabel 7 Porposi Responden Berdasarkan Penerapan Sistem RFID

\begin{tabular}{llll}
\hline No & Penerpan sistem RFID & Jumlah & Presentase (\%) \\
\hline $\mathbf{1}$ & Setuju & 182 & 91 \\
$\mathbf{2}$ & Tidak Setuju & 18 & 9 \\
\hline Jumlah & 200 & 100 \\
\hline
\end{tabular}

Data Responden Tentang Implementasi RFID Mobil Di Kawasan UNS.

Adapun hasil di penelitian untuk rekomendasi implementasi RFID dapat dilihat pada tabel :

Tabel 8 Rekomendasi Operasional Sistem RFID

\begin{tabular}{|c|c|c|c|c|c|}
\hline \multirow[t]{2}{*}{ No } & \multirow[t]{2}{*}{ Kondisi } & \multicolumn{3}{|c|}{ Usalan Operasional } & \multirow[t]{2}{*}{ Rekomendasi } \\
\hline & & Usulan & Jumlah & $\begin{array}{l}\text { Presentase } \\
(\%)\end{array}$ & \\
\hline 1 & $\begin{array}{l}\text { jika dosen / karyawan } \\
\text { lupa membawa kartu } \\
\text { tag (smard card) tetapi } \\
\text { kendaran bermotor } \\
\text { sudah tercatat }\end{array}$ & $\begin{array}{l}\text { Menggunakan } \\
\text { kartu sementara } \\
\text { Membayar }\end{array}$ & $\begin{array}{l}132 \\
50\end{array}$ & 27 & $\begin{array}{l}\text { Menggunakan } \\
\text { kartu } \\
\text { sementara }\end{array}$ \\
\hline 2 & $\begin{array}{l}\text { jika seseorang dosen / } \\
\text { karyawan membawa } \\
\text { kartu tag (smard card) } \\
\text { tetapi } \\
\text { bermotor } \\
\text { tercatat }\end{array}$ & $\begin{array}{l}\text { Menggunakan } \\
\text { kartu sementara } \\
\text { Membayar }\end{array}$ & 84 & 46 & Membayar \\
\hline 3 & $\begin{array}{lr}\text { mahasiswa } & \text { tahun } \\
\text { berapakah yang boleh } \\
\text { melakukan pencatatan } \\
\text { kendaran } & \text { dan } \\
\text { mempunyai } & \text { Tag } \\
\text { (Smard card) } & \end{array}$ & $\begin{array}{l}\text { Semua } \\
\text { Lebih dari } \\
1 \text { tahun } \\
\text { Tidak } \\
\text { dipernolehkan } \\
\text { membawa } \\
\text { mobil }\end{array}$ & $\begin{array}{l}59 \\
42 \\
81\end{array}$ & $\begin{array}{l}32 \\
23 \\
45\end{array}$ & $\begin{array}{l}\text { Tidak } \\
\text { dipernolehkan } \\
\text { membawa } \\
\text { mobil }\end{array}$ \\
\hline 4 & $\begin{array}{l}\text { jika mahasiswa lupa } \\
\text { membawa kartu tag } \\
\text { (smard card) tetapi } \\
\text { kendaran bermotor } \\
\text { sudah tercatat }\end{array}$ & $\begin{array}{l}\text { Menggunakan } \\
\text { kartu sementara } \\
\text { Membayar } \\
\text { Tidak } \\
\text { diperbolehkan } \\
\text { membawa } \\
\text { mobil } \\
\end{array}$ & $\begin{array}{l}79 \\
78 \\
25\end{array}$ & $\begin{array}{l}43 \\
43 \\
14\end{array}$ & $\begin{array}{l}\text { Menggunakan } \\
\text { kartu } \\
\text { sementara }\end{array}$ \\
\hline 5 & $\begin{array}{lr}\text { jika } & \text { seseorang } \\
\text { mahasiswa } & \text { membawa } \\
\text { kartu tag } & \text { (smard card) } \\
\text { tetapi } & \text { kendaran } \\
\text { bermotor } & \text { belum } \\
\text { tercatat } & \\
\end{array}$ & $\begin{array}{l}\text { Menggunakan } \\
\text { kartu sementara } \\
\text { Membayar } \\
\text { Tidak } \\
\text { diperbolehkan } \\
\text { membawa }\end{array}$ & $\begin{array}{l}46 \\
58 \\
74\end{array}$ & $\begin{array}{l}33 \\
41\end{array}$ & $\begin{array}{l}\text { Tidak } \\
\text { diperbolehkan } \\
\text { membawa } \\
\text { mobil }\end{array}$ \\
\hline
\end{tabular}




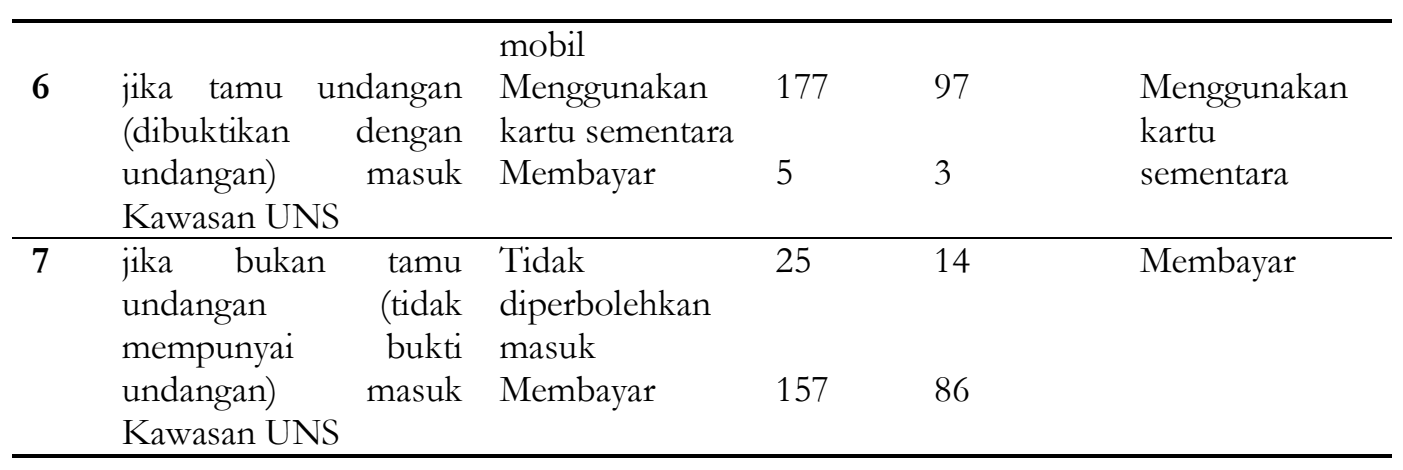

\section{KESIMPULAN}

Dari hasil analisis yang telah dilakukan dapat disimpulkan bahwa :

1. Ketersedian Satuan Ruang Parkir (SRP) di kawasan UNS adalah 1283 mobul, sedangkan kebutuhan Satuan Ruang Parkir (SRP) maksimal adalah 860 mobil,pada dasarnya cukup.

2. Potensi implementasi sistem RFID mobildi kawasan UNS menurut hasil analisis responden 91\% setuju terhadap implementasi tersebut, yang terdiri dari 57\% laki - laki dengan frekuensi terbanyak 5 kali dalam seminggu dengan prosentase sebsar $50 \%$ dan usia 18-27 tahun dengan prosentasae sebesar 50\%.

3. Rekomendasi implementasi mobil di kawasan UNS dapat disimpulkan bahwa :

a. Jika dosen / karyawan lupa membawa kartu tag (smard card) tetapi kendaran bermotor sudah tercatat adalah menggunkan kartu sementara.

b. Jika seseorang dosen / karyawan membawa kartu tag (smard card) tetapi kendaran bermotor belum tercatat adalah memebayar.

c. Mahasiswa tahun berapakah yang boleh melakukan pencatatan kendaran dan mempunyai Tag (Smard card) adalah tidak diperbolehkan membawa mobil.

d. Jika mahasiswa lupa membawa kartu tag (smard card) tetapi kendaran bermotor sudah tercatat adalah membayar atau menggunakan kartu sementara.

e. Jika seseorang mahasiswa membawa kartu tag (smard card) tetapi kendaran bermotor belum tercatat adalah tidak diperbolehkan masuk.

f. Jika tamu undangan (dibuktikan dengan undangan) masuk Kawasan UNS adalah menggunkan kartu sementara.

g. Jika bukan tamu undangan (tidak mempunyai bukti undangan) masuk kawasan UNS adalah membayar. 


\section{DAFTAR PUSTAKA}

Pedoman Perencanaan dan Pengoperasian Fasilitas Parkir, Direktorat Jenderal Perhubungan Darat 1998

Valentin DKK, 2006, “ Mengoptimalkan akses dan layanan kmapus dengan menggunakan solusi RFID”, Internatiomal conference on DEVELOPMENT AND APPLICATION SYSTEMS

Hamid, 2010, "Pengembangan sistem parkir terkomputerisasi dengan otomatisai pembiayaan dan penggunaan RFID sebagai pengenal untuk penguna", Prosiding SNATI 2010

Hunt, V. D., Puglia, Albert., dan Puglia, Mike. 2007. RFID - A Guide to Radio Frequency Identification. John Wiley \& Sons

Manish, Bhuptani dan Moradpour Shahram. 2005. RFID Field Guide: Deploying Radio Frequency Identification Systems. Prentice Hall PTR.

Roswiany Mutiara Hartwanty , 2011, "Sistem pengaturan parkir di kampus c Universitas Baturaja", Vol 1, no 1 hal 31-43

Andy Prasewtyo Utomo, 2013, “Analisa dan perancangan sistem informasi parkir di Universitas Muria Kudus “, Vol 3No 1ISSN: 2252-4983

Bobby Kurniawan dkk ,2014," Perbaikan sistem parkir kendaraan bermotor di lingkungan Universitas Komputer Indonesia dengan menggunakan RFID dan database", Vol 12 No 2 Hal 125-133 